\title{
MRAS Speed Estimator Based on Type-1 and Type-2 Fuzzy Logic Controller for the Speed Sensorless DTFC-SVPWM of an Induction Motor Drive
}

\author{
Tejavathu Ramesh ${ }^{\dagger}$, Anup Kumar Panda*, and S. Shiva Kumar \\ ${ }^{\dagger}$ Department of Electrical Engineering, National Institute of Technology Kurukshetra, Haryana, India \\ *Department of Electrical Engineering, National Institute of Technology Rourkela, Orissa, India
}

\begin{abstract}
This paper presents model reference adaptive system speed estimators based on Type- 1 and Type- 2 fuzzy logic controllers for the speed sensorless direct torque and flux control of an induction motor drive (IMD) using space vector pulse width modulation. A Type-1 fuzzy logic controller (T1FLC) based adaptation mechanism scheme is initially presented to achieve high performance sensorless drive in both transient as well as in steady-state conditions. However, the Type- 1 fuzzy sets are certain and cannot work effectively when a higher degree of uncertainties occurs in the system, which can be caused by sudden changes in speed or different load disturbances and, process noise. Therefore, a new Type-2 FLC (T2FLC) - based adaptation mechanism scheme is proposed to better handle the higher degree of uncertainties, improve the performance, and is also robust to different load torque and sudden changes in speed conditions. The detailed performance of different adaptation mechanism schemes are performed in a MATLAB/Simulink environment with a speed sensor and sensorless modes of operation when an IMD is operates under different operating conditions, such as no-load, load, and sudden changes in speed. To validate the different control approaches, the system is also implemented on a real-time system, and adequate results are reported for its validation.
\end{abstract}

Key words: Direct Torque and Flux Control, Induction Motor Drive, Model Reference Adaptive System, Type-1 Fuzzy Logic Controller, Type-2 Fuzzy Logic Controller

\section{INTRODUCTION}

Induction motor drives (IMDs) have made significant inroads in recent times because of their robustness and rugged structure. IMDs are widely used in industrial applications, such as electric and hybrid vehicles and traction locomotives. The field-oriented control (FOC) of an IMD offers a satisfactory steady-state and transient response, and works similar to a separately excited DC motor [1], [2]. However, the FOC method suffers from several drawbacks, such as the requirement of co-ordinate transformations and current controllers. Therefore, a new control strategy called direct torque and flux control (DTFC) scheme was introduced to overcome the above drawbacks [3].

Manuscript received Nov. 24, 2014; accepted Feb. 15, 2015

Recommended for publication by the Associate Editor Shihua Li.

${ }^{\dagger}$ Corresponding Author: tramesh.ee@gmail.com

Tel/Fax: +91-9778798543, National Institute of Technology Kurukshetra

*Dept. of Electrical Eng., Nat'l Institute of Technology Rourkela, India
The DTFC of an IMD requires the rotor speed information for accurate speed control. The rotor shaft position can be measured through either speed sensors (i.e., encoder/tachometer) or from an estimator/observer that uses current and voltage signals. The use of speed sensors is associated with several drawbacks, such as the requirement of a shaft extension, reduction in mechanical robustness of the motor drive, reduction in drive reliability, nonsuitabality for hostile environments, and high cost [4]-[6]. These drawbacks have increased the attraction for the speed sensorless DTFC of IMDs over that for the conventional DTFC of IMDs [5]-[17].

Several methods have been proposed to estimate the rotor speed of sensorless IMDs in past years [6]-[17], including signal injection method [6], state observer method [7], [8], and model reference adaptive system (MRAS) method [9]-[16]. Among these methods, MRAS-based speed estimation is the most commonly employed strategy because of its attractive features and simplicity unlike the other 
methods [9]-[16].

The performance of rotor speed estimation depends on the design of the adaptation control scheme [16]-[29]. A literature survey reveals that numerous studies have used different controllers to improve drive performance, such as proportional integral controller (PIC), sliding mode control (SMC), neuro-fuzzy control (NFC), and conventional Type-1 fuzzy logic controller (T1FLC). PIC offers suitable performance on ideal operations. However, it requires a precise mathematical model, continuous tuning, and accurate gain values of proportional $\left(K_{p}\right)$ and integral $\left(K_{i}\right)$ variables to achieve high-performance drive [7]-[11]. SMC offers satisfactory performance [12], [15], [16]. However, the use of a signum function results in a high-frequency chattering phenomenon because of discontinuous control action, which creates the said problem when the system state is near the sliding surface. The T1FLC and NF controllers improve drive performance [17]-[21]. However, NFC and T1FLC use 2D control, which cannot work effectively when a higher degree of uncertainties occurs in the system. Therefore, a new type of fuzzy logic control strategy, called the Type-2 fuzzy logic control (T2FLC) system, is introduced to overcome the above drawbacks [22]-[29].

This paper presents the T1FLC- and T2FLC-based MRAS speed estimator for the speed sensorless DTFC of an IMD that uses the space vector pulse width modulation technique (SVPWM). First, the T1FLC-based adaptation scheme is implemented to obtain high-performance sensorless drive [17]. However, the Type- 1 fuzzy sets are certain and cannot work effectively when a higher degree of uncertainties occurs in the system, which can be caused by sudden changes in speed or by different load torque disturbances and process noise [22]-[29]. Therefore, a T2FLC-based adaptation scheme is proposed to overcome the above drawbacks, which is sufficiently robust to different load torque and sudden changes in speed disturbances. The performance of each adaptation scheme is tested and compared based on MATLAB/Simulink, as well as in a real-time system with speed sensor and sensorless modes of operation under sudden changes in speed and different load torque conditions respectively. The real-time system is implemented using a typical IMD with a power rating of $1.5 \mathrm{~kW}$ and a dSPACE-1104 controller board with an ADC interface board CP1104.

\section{DIRECT TORQUE AND FLUX CONTROL}

\section{A. Mathematical Modeling of an IMD}

An IMD mathematical model was developed [1]-[3] using stator and rotor flux linkages, which are referred to by a stationary reference frame using the superscript "p.” The state space matrix is shown as follows:

$$
\begin{aligned}
& \frac{\mathrm{d}}{\mathrm{dt}}(\mathrm{X})=\mathrm{AX}+\mathrm{BU} \\
& \mathrm{A}=\frac{1}{\mathrm{~L}_{\sigma}}\left[\begin{array}{cccc}
-\mathrm{R}_{\mathrm{s}} \mathrm{L}_{\mathrm{r}} & \omega_{\mathrm{r}} \mathrm{L}_{\mathrm{m}}^{2} & \mathrm{R}_{\mathrm{r}} \mathrm{L}_{\mathrm{m}} & \omega_{\mathrm{r}} \mathrm{L}_{\mathrm{r}} \mathrm{L}_{\mathrm{m}} \\
-\omega_{\mathrm{r}} \mathrm{L}_{\mathrm{m}}^{2} & -\mathrm{R}_{\mathrm{s}} \mathrm{L}_{\mathrm{r}} & -\omega_{\mathrm{r}} \mathrm{L}_{\mathrm{r}} \mathrm{L}_{\mathrm{m}} & \mathrm{R}_{\mathrm{r}} \mathrm{L}_{\mathrm{m}} \\
\mathrm{L}_{\mathrm{m}} \mathrm{R}_{\mathrm{s}} & -\omega_{\mathrm{r}} \mathrm{L}_{\mathrm{s}} \mathrm{L}_{\mathrm{m}} & -\mathrm{R}_{\mathrm{r}} \mathrm{L}_{\mathrm{s}} & -\omega_{\mathrm{r}} \mathrm{L}_{\mathrm{s}} \mathrm{L}_{\mathrm{r}} \\
\omega_{\mathrm{r}} \mathrm{L}_{\mathrm{s}} \mathrm{L}_{\mathrm{m}} & \mathrm{R}_{\mathrm{s}} \mathrm{L}_{\mathrm{m}} & \omega_{\mathrm{r}} \mathrm{L}_{\mathrm{s}} \mathrm{L}_{\mathrm{r}} & -\mathrm{R}_{\mathrm{r}} \mathrm{L}_{\mathrm{s}}
\end{array}\right] \\
& B=\frac{1}{L_{\sigma}}\left[\begin{array}{cc}
\mathrm{L}_{\mathrm{r}} & 0 \\
0 & \mathrm{~L}_{\mathrm{r}} \\
-\mathrm{L}_{\mathrm{m}} & 0 \\
0 & -\mathrm{L}_{\mathrm{m}}
\end{array}\right] \\
& \mathrm{X}=\left[\begin{array}{llll}
\mathrm{i}_{\mathrm{ds}}^{\mathrm{p}} & \mathrm{i}_{\mathrm{qs}}^{\mathrm{p}} & \mathrm{i}_{\mathrm{dr}}^{\mathrm{p}} & \mathrm{i}_{\mathrm{qr}}^{\mathrm{p}}
\end{array}\right]^{\mathrm{T}} ; \quad \mathrm{U}=\left[\begin{array}{llll}
\mathrm{U}_{\mathrm{ds}}^{\mathrm{p}} & \mathrm{U}_{\mathrm{qs}}^{\mathrm{p}} & 0 & 0
\end{array}\right]^{\mathrm{T}}
\end{aligned}
$$

Stator flux ( $\hat{\psi}_{\mathrm{s}}$ ) can be estimated using the measured stator current and voltages provided by the following:

$$
\hat{\psi}_{\mathrm{s}}=\sqrt{\left(\psi_{\mathrm{ds}}^{\mathrm{p}^{2}}+\psi_{\mathrm{qs}}^{\mathrm{p}^{2}}\right)}
$$

where $\psi_{\mathrm{ds}}^{\mathrm{p}}=\int\left(\mathrm{U}_{\mathrm{ds}}^{\mathrm{p}}-\mathrm{i}_{\mathrm{ds}}^{\mathrm{p}} \mathrm{R}_{\mathrm{s}}\right) \mathrm{dt}$ and $\psi_{\mathrm{qs}}^{\mathrm{p}}=\int\left(\mathrm{U}_{\mathrm{qs}}^{\mathrm{p}}-\mathrm{i}_{\mathrm{qs}}^{\mathrm{p}} \mathrm{R}_{\mathrm{s}}\right) \mathrm{dt}$.

The expressions of estimated electromagnetic torque and angle between the stator and rotor flux are as follows:

$$
\begin{aligned}
& \hat{\mathrm{T}}_{\mathrm{e}}=\frac{3}{2} \frac{\mathrm{P}}{2}\left(\psi_{\mathrm{ds}}^{\mathrm{p}} \mathrm{i}_{\mathrm{qs}}^{\mathrm{p}}-\psi_{\mathrm{qs}}^{\mathrm{p}} \mathrm{i}_{\mathrm{ds}}^{\mathrm{p}}\right) \\
& \hat{\theta}_{\mathrm{e}}(\mathrm{k})=\tan ^{-1}\left(\frac{\psi_{\mathrm{qs}}^{\mathrm{p}}}{\psi_{\mathrm{ds}}^{\mathrm{p}}}\right)
\end{aligned}
$$

where $\partial=\mathrm{d} / \mathrm{dt} ; \mathrm{L}_{\sigma}=\mathrm{L}_{\mathrm{s}} \mathrm{L}_{\mathrm{r}}-\mathrm{L}_{\mathrm{m}}^{2} ; \mathrm{i}_{\mathrm{ds}}, \mathrm{i}_{\mathrm{dr}}$ are the d-axis stator and rotor current respectively; $i_{q s}, i_{q r}$ are the q-axis stator and rotor current respectively; $\psi_{\mathrm{ds}}, \psi_{\mathrm{dr}}$ are the d-axis stator and rotor flux linkages respectively; $\psi_{\mathrm{qs}}, \psi_{\mathrm{qr}}$ are the q-axis stator and rotor flux linkages respectively; $\mathrm{L}_{\mathrm{s}}, \mathrm{L}_{\mathrm{r}}$ are the stator and rotor equivalent inductances respectively; $\mathrm{L}_{\mathrm{m}}$ is the mutual inductance; $\mathrm{R}_{\mathrm{s}}, \mathrm{R}_{\mathrm{r}}$ are the stator and rotor resistances respectively; $\mathrm{P}$ is the pole number; and $\mathrm{T}_{\mathrm{e}}$ is the electromagnetic torque.

\section{B. Space Vector Pulse-Width Modulation}

The schematic of an MRAS speed estimator for sensorless DTFC of an IMD that uses SVPWM is shown in Fig. 1. The voltage source inverter has eight possible state vectors (i.e., six active and two zero), where six active vectors generate six active voltage vectors $\left(U_{1}\right.$ to $\left.U_{6}\right)$ with equal magnitude and are divided into six sectors. Each sector phase is displaced by $60^{\circ}$ in the space vector plane. The reference vector $\left(u_{r e f}\right)$ is positioned in the first sector as shown in Fig. 2(a). The six active vectors times $\left(t_{1}\right.$ to $\left.t_{2}\right)$ and two zero vector times $\left(t_{z}\right)$ are determined using the volt-second balance principle [22]. The switching pulses generated using Eqs. (5)-(7) in the first sector for a given sampling time are shown in Fig. 2(b). The said process is repeated for a complete full cycle to generate the switching pulses for the remaining five sectors [22].

$$
\mathrm{t}_{1}=\frac{\sqrt{3} * \mathrm{t}_{\mathrm{s}} * \mathrm{u}_{\mathrm{ref}}}{\mathrm{u}_{\mathrm{DC}}}\left(\sin \left(\frac{\pi}{3}-\alpha\right)\right)
$$




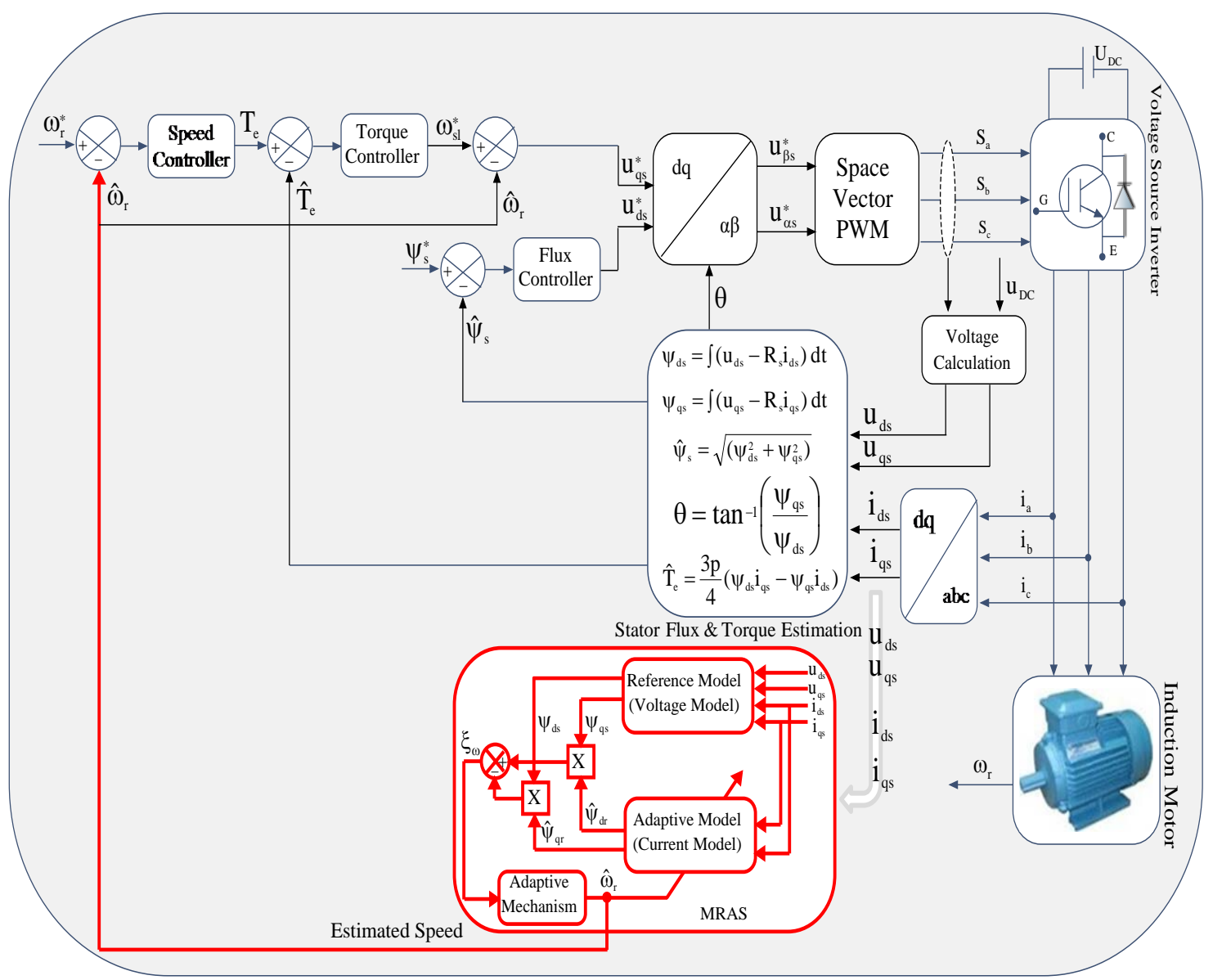

Fig. 1. Schematic of a rotor-flux MARS speed estimator for the speed sensorless DTFC-SVPWM of an IMD.

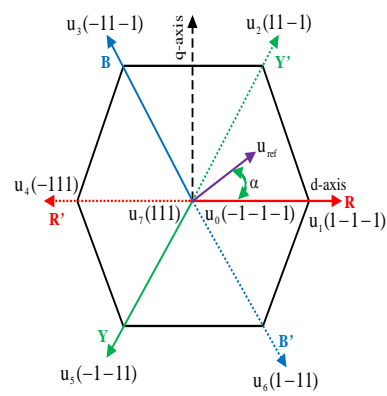

(a)

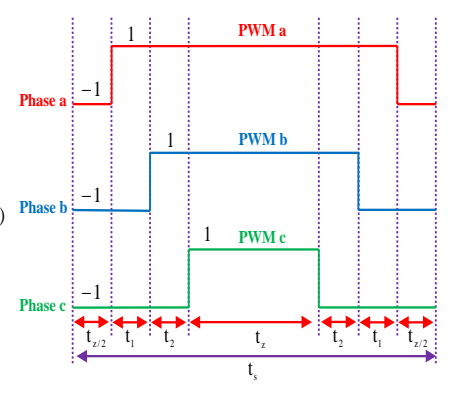

(b)
Fig. 2. Schematic model of SVPWM: (a) voltage vector switching states. (b) Upper leg PWM of the three-phase voltage source inverter when the reference vector is in the first sector.

$$
\begin{gathered}
\mathrm{t}_{2}=\frac{\sqrt{3} * \mathrm{t}_{\mathrm{s}} * \mathrm{u}_{\mathrm{ref}}}{\mathrm{u}_{\mathrm{DC}}}(\sin \alpha) \\
\mathrm{t}_{\mathrm{z}}=\mathrm{t}_{\mathrm{s}}-\mathrm{t}_{1}-\mathrm{t}_{2}
\end{gathered}
$$

\section{ROTOR-FLUX MRAS SPEED ESTIMATOR}

The IMD speed can be estimated using the rotor-flux MRAS speed estimator scheme. This estimator scheme is initially introduced using the voltage model (VM) as a reference model (RM) and the current model (CM) as an adjustable model (AM). The RM is independent of the rotor speed, whereas the AM is dependent on the rotor speed [16]. The outputs of these two models are used to generate the speed tuning error signal, which is fed into the adaptation mechanism. The adaptation mechanism is used to generate the estimated rotor speed and is fed back into the AM, which is updated by producing the proper rotor speed estimation until the error reaches zero. The process of updating the AM continues until the error signal between the RM and AM reaches zero and the rotor speed estimation accurately tracks the reference speed [7]-[13].

The reference values of rotor flux in the RM are generated using the stator voltage and current components. The reference rotor flux components (in the form of d- and q-axis) can be obtained from the RM as follows [11], [12]:

$$
\left[\begin{array}{l}
\partial \psi_{\mathrm{dr}}^{\mathrm{p}} \\
\partial \psi_{\mathrm{qr}}^{\mathrm{p}}
\end{array}\right]=\frac{\mathrm{L}_{\mathrm{r}}}{\mathrm{L}_{\mathrm{m}}}\left\{\left[\begin{array}{l}
\partial \psi_{\mathrm{ds}}^{\mathrm{p}} \\
\partial \psi_{\mathrm{qs}}^{\mathrm{p}}
\end{array}\right]-\left[\begin{array}{cc}
\sigma \partial \mathrm{L}_{\mathrm{s}} & 0 \\
0 & \sigma \partial \mathrm{L}_{\mathrm{s}}
\end{array}\right]\left[\begin{array}{c}
\mathrm{i}_{\mathrm{ds}}^{\mathrm{p}} \\
\mathrm{i}_{\mathrm{qs}}^{\mathrm{p}}
\end{array}\right]\right\}
$$

The estimated rotor flux components in the AM are generated using both stator current and estimated rotor speeds. The estimated rotor flux components (in the form of d- and 


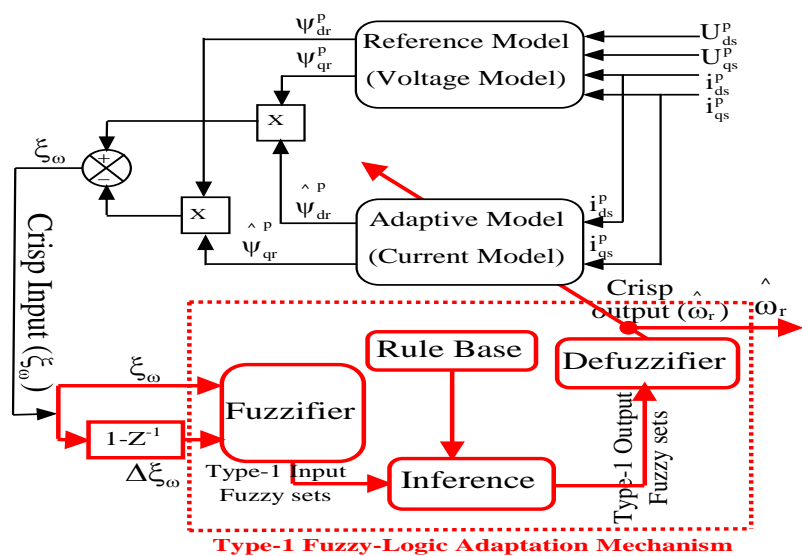

Fig. 3. Schematic of the T1FLC-based rotor-flux MRAS speed estimator.

q-axis) can be obtained from the AM as follows:

$$
\left[\begin{array}{c}
\partial \hat{\psi}_{\mathrm{dr}}^{\mathrm{p}} \\
\partial \hat{\psi}_{\mathrm{qr}}^{\mathrm{p}}
\end{array}\right]=\left[\begin{array}{cc}
-\frac{1}{\tau_{\mathrm{r}}} & -\hat{\omega}_{\mathrm{r}} \\
\hat{\omega_{\mathrm{r}}} & -\frac{1}{\tau_{\mathrm{r}}}
\end{array}\right]\left[\begin{array}{c}
\hat{p}_{\mathrm{p}}^{\mathrm{p}} \\
\hat{\mathrm{dr}}^{\mathrm{p}} \\
\psi_{\mathrm{qr}}
\end{array}\right]+\frac{\mathrm{L}_{\mathrm{m}}}{\tau_{\mathrm{r}}}\left[\begin{array}{c}
\mathrm{i}_{\mathrm{ds}}^{\mathrm{p}} \\
\mathrm{i}_{\mathrm{qs}}^{\mathrm{p}}
\end{array}\right]
$$

The expression for the speed tuning error signal can be obtained as follows:

$$
\xi_{\omega}=\left(\hat{\psi}_{\mathrm{dr}}^{\mathrm{p}} * \psi_{\mathrm{qr}}^{\mathrm{p}}\right)-\left(\hat{\psi}_{\mathrm{qr}}^{\mathrm{p}} * \psi_{\mathrm{dr}}^{\mathrm{p}}\right)
$$

where $\tau_{\mathrm{r}}=\mathrm{L}_{\mathrm{r}} / \mathrm{R}_{\mathrm{r}}, \partial=\mathrm{d} / \mathrm{dt}$, and “^ ” indicates the estimation signal.

The estimated rotor speed is obtained from the adaptation mechanism scheme by feeding the speed tuning error signal obtained from Eq. (10).

\section{A. T1FLC-Based MRAS Speed Estimator}

T1FLC can handle complicated nonlinear systems and does not require precise mathematical modeling and gain values unlike constant gain PIC, making the T1FLC suitable for speed sensorless drives [12], [16]-[21]. The schematic model of the MRAS speed estimator that uses T1FLC-based adaptation mechanism is shown in Fig. 3.

The speed tuning error signal fed into the T1FLC determines the rotor speed estimation. The input and output variables of a T1FLC are the speed tuning error signal “ $\xi_{\omega}$," which is shown in Eq. (10), and the rate of change in the speed tuning error signal “ $\Delta \xi_{\omega}$," which is shown in Eq. (11).

The output variable is the estimated rotor speed " $\hat{\omega}_{\mathrm{r}}$ ". The

Mamdani-type triangular membership functions are considered for the input and output variables. Two-input and single-output variables are obtained. Each variable has seven linguistic variables, including as negative large (NL), negative medium (NM), negative small (NS), zero (ZE), positive small (PS), positive medium (PM), and positive large (PL). The T1FLC rule base is depicted in Table I.
TABLE I

Rule Base of A Type-1 Fuzzy Logic Controller

\begin{tabular}{|c|c|c|c|c|c|c|c|}
\hline$\xi_{\omega} \Delta \xi_{\omega}$ & NL & NM & NS & ZE & PS & PM & PL \\
\hline NL & NL & NL & NL & NM & NS & NS & ZE \\
\hline NM & NL & NL & NM & NM & NS & ZE & PS \\
\hline NS & NL & NM & NS & NS & ZE & PS & PM \\
\hline ZE & NL & NM & NS & ZE & PS & PM & PL \\
\hline PS & NM & NS & ZE & PS & PS & PM & PL \\
\hline PM & NS & ZE & PS & PM & PM & PL & PL \\
\hline PL & ZE & PS & PS & PM & PL & PL & PL \\
\hline
\end{tabular}

$$
\Delta \xi_{\omega}(\mathrm{k})=\xi_{\omega}(\mathrm{k})-\xi_{\omega}(\mathrm{k}-1)
$$

1) Design of Defuzzification: The rules for T1FLC generation require output in a linguistic variable according to real-world requirements, and linguistic variables have to be transformed to crisp output.

$$
\mu_{\mathrm{A}}(\mathrm{x})=\operatorname{defuzz}(\mathrm{x}, \mathrm{mf}, \mathrm{type})
$$

where defuzz (x, mf, type) returns a defuzzified value out of an MF positioned at the associated variable value $x$ that uses one of several defuzzification strategies on the basis of the argument type. This result should be defuzzified to obtain a final crisp output. The mathematical expression of center of area can have a discretized universe of discourse, whose expression is as follows:

$$
\operatorname{COA}=\frac{\sum_{\mathrm{i}=1}^{\mathrm{n}} \mu_{\mathrm{A}}\left(\mathrm{x}_{\mathrm{i}}\right) \mathrm{x}_{\mathrm{i}}}{\sum_{\mathrm{i}=1}^{\mathrm{n}} \mu_{\mathrm{A}}\left(\mathrm{x}_{\mathrm{i}}\right)}
$$

The triangular curve is a function of the vector $x$ and depends on the three scalar parameters $a, b$, and $c$ as follows:

$$
\mu_{A}(x)=\max \left(\min \left(\frac{x-a}{b-a}\right),\left(\frac{c-x}{c-b}\right), 0\right)
$$

\section{B. T2FLC-Based MRAS Speed Estimator}

T1FLCs have been applied in different applications with significant success to date. However, surviving with large amounts of uncertainties is necessary for dynamic unstructured environments and different real-world applications. The T1FLC cannot minimize the higher amount of uncertainty through crisp Type-1 fuzzy sets (T1FSs). A T2FLC that uses Type-2 FSs (T2FSs) can overcome the drawbacks of T1FLCs. T2FLC was introduced by Lotfali Askar Zadeh in 1975. T2FSs are used for different uncertainty and imprecision levels in a better way. T2FLCs are essentially "fuzzy-fuzzy" sets, where the fuzzy degree of membership is a T1FS [12-24]. The new T2FLC was developed to obtain high-performance sensorless drive and cope with nonlinearities, sudden change in speed, and load torque disturbance rejections. The T2FLC structure is similar to the T1FLC structure, but their difference lies in the crisp output value block. The output value block in the T1FLC only contains a defuzzifier, but the crisp output processing 


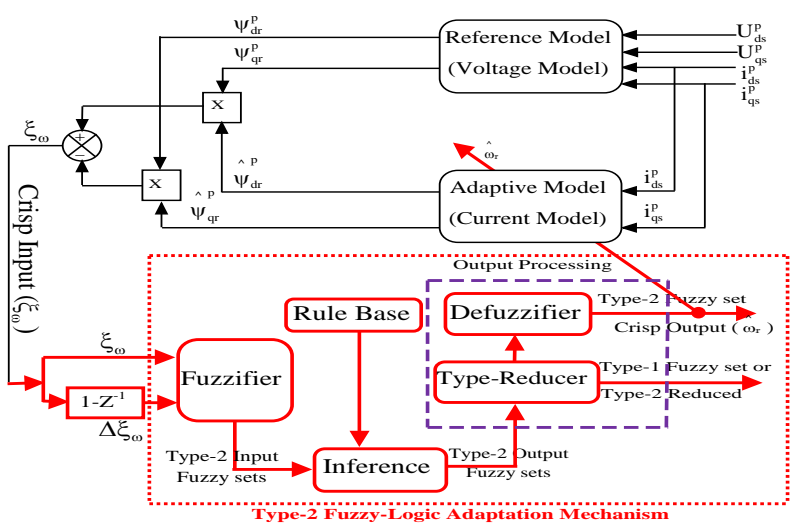

Fig. 4. Schematic model of the T2FLC-based MRAS speed estimator.

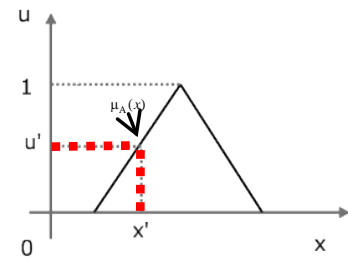

(a)

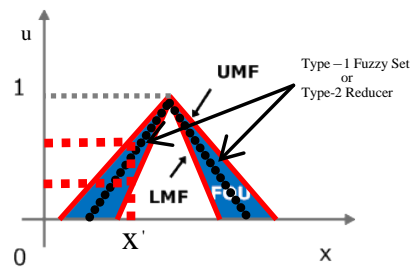

(b)
Fig. 5. Triangular MFs with uncertain widths: (a) T1FLC and (b) T2FLC.

value block in the T2FLC includes a type reducer (Type-2 reducer or T1FSs) [24]-[29]. A type reducer is required to convert the output value of the fuzzy inference engine into T1FSs called the type-reduce set, which is defuzzified to obtain the crisp output value. The membership function (MF) of a TF1S being crisp means that the degree of membership sets is completely crisp and not fuzzy. The schematic of the T2FLC-based MRAS speed estimator is shown in Fig. 4.

1) Design of a T2FLC Rule Base: A new concept [23]-[25] allows the characterization of a T2FS with a better MF and an inferior MF. These two functions can each be represented by T1FS MFs. The interval between these two functions represents the foot point of uncertainty (FOU), which is used to characterize a T2FS [26]. The membership grade for each element in a T1FLC is a crisp number in $[0,1]$, and the MF in a T2FS is characterized by a 3D MF with an FOU. The major difference between the T1FLC and T2FLC systems is in the nature of the MFs, which are shown in Figs. 5(a) and 5(b) respectively. The FOU offers an additional degree of freedom to handle parameter variations. The T2FLC design configuration is similarly selected as that of the T1FLC. Two-input and single-output variables are obtained, each with the seven linguistic variables listed in Table I.

The antecedent and consequent of the T2FLC with triangular MFs are shown in Fig. 6. The universes of discourse of the input and output variables are normalized in the interval of $[-1,1]$. The T2FS operation is identical to an operation on T1FLS. However, fuzzy operation is conducted

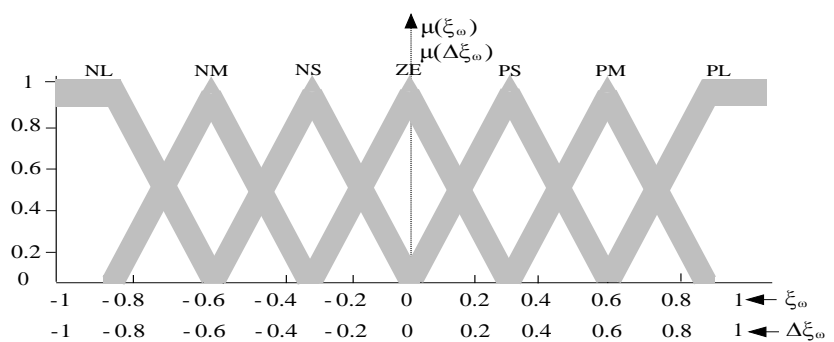

(a)

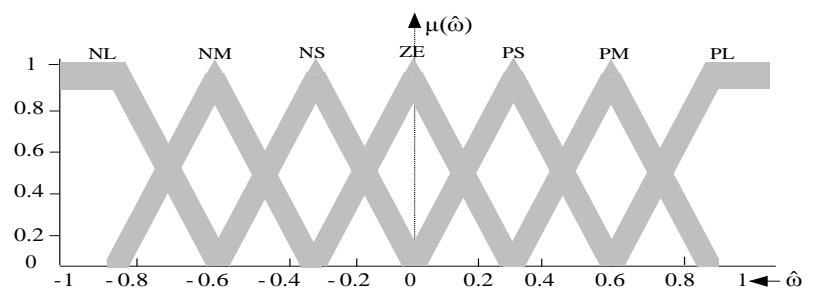

(b)

Fig. 6. T2FS input and output variables. (a) error speed tuning signal $\left(\xi_{\omega}\right)$ and change in error speed tuning signal $\left(\Delta \xi_{\omega}\right)$. (b) rotor speed estimator $\left(\hat{\omega}_{\mathrm{r}}\right)$.

on the Type-2 fuzzy system at two Type- 1 MFs that limit the FOU, upper MF (UMF), and lower MF (LMF) to produce firing strengths. Thus, the membership value for each element of this set is a fuzzy set in $[0,1]$.

The T2FS is bounded from the top by a UMF and bounded from the bottom by an LMF. The FOU is the area between the LMF and UMF. The FOU and new third dimension of the T2FSs offer additional degrees of freedom that allow direct control and handling of a higher degree of uncertainties. Thus, T2FLC that uses T2FSs in either their input or output variables have the potential to provide a suitable framework to handle the parameter uncertainties in real world environments [22]-[29]. Notably, a T2FS embeds a large number of T1FLS. The T1FLS is denoted by " $A$ " and the membership grade (a synonym for the degree of membership) of $x \in \mathrm{X}$ in $A$ is $\mu_{\mathrm{A}}(x)$, which is a crisp number in $[0,1]$. A T2FS in " $X$ " is " $\tilde{\mathrm{A}}$ " and the membership grade of " $\tilde{\mathrm{A}}$ " in $x \in X$ is $\mu_{\tilde{\mathrm{A}}}(x)$, which is a T1FS in $[0,1]$. The T2FS is denoted by “ $\tilde{\mathrm{A}}$," which is characterized by a Type-2 M. $\mu_{\tilde{\mathrm{A}}}(x, u)$, where $x \in \mathrm{X}$ and $\mathrm{u} \in \mathrm{J}_{x} \subseteq[0,1]$, i.e.,

$$
\widetilde{A}=\left\{(x, \mathrm{u}), \mu_{\tilde{\mathrm{A}}}(x, \mathrm{u}) \mid \forall_{x} \in \mathrm{X}, \forall \mathrm{u} \in \mathrm{J}_{x} \subseteq[0,1]\right\}
$$

in which $0 \leq \mu_{\tilde{\mathrm{A}}}(x, \mathrm{u}) \leq 1$. " $\widetilde{\mathrm{A}}$ " can also be expressed as

$$
\tilde{A}=\int_{x \in X} \int_{u \in J_{x}} \mu_{\tilde{\mathrm{A}}}(x, \mathrm{u}) /(x, \mathrm{u}) \quad \mathrm{J}_{x} \subseteq[0,1]
$$

where “ $\iint$ ” denotes union over all admissible “ $x$ ” and “ $u$ ”. For a discrete universe of discourse, “ $\int$ ” is replaced by “ $\Sigma$ ”. The expression of “ $\tilde{\mathrm{A}}$ ” can be re-expressed as follows: 


$$
\tilde{A}=\int_{x \in X} \mu_{\tilde{\mathrm{A}}}(x) / x=\int_{x \in X}\left[\int_{u \in J_{x}} f_{x}(u) / u\right] / x \quad \mathrm{~J}_{x} \subseteq[0,1]
$$

If " $X$ ” and " $\mathrm{J}_{X}$ " are both discrete, then

$$
\begin{aligned}
& \tilde{A}=\sum_{K=1}^{M_{1}}\left[\sum_{u \in J_{X_{1}}} f_{x_{1}}\left(u_{1 k}\right) / u_{1 k}\right] / x_{2}+\sum_{K=2}^{M_{2}}\left[\sum_{u \in J_{X_{2}}} f_{x_{2}}\left(u_{2 k}\right) / u_{2 k}\right] / x_{2} \\
& +\ldots \ldots . . .+\sum_{K=N}^{M_{N}}\left[\sum_{u \in J_{X_{N}}} f_{x_{N}}\left(u_{1 N}\right) / u_{1 N}\right] / x_{N}
\end{aligned}
$$

The symbol "+" also denotes union in Eq. (18). Note that “ $x$ ” has been discretized into the " $N$ " value of " $u$," and each of these values has been discretized into “ $\mathrm{M}_{i}$ ” values. The discretization along each " $\mathrm{u}_{i k}$ ” does not have to be the same, which is why we show a different upper sum for each of the bracketed terms. However, if the discretization along each " $\mathrm{u}_{i k}$ " is the same, then $\mathrm{M}_{1}=\mathrm{M}_{2}=\ldots=\mathrm{M}_{\mathrm{N}}=\mathrm{M}$.

Uncertainty in the primary memberships of a T2FS “ $\tilde{\mathrm{A}}$ " consists of a bounded region called the FOU, which is the union of all primary memberships:

$$
\operatorname{FOU}(\tilde{\mathrm{A}})=\mathrm{U}_{x \in \mathrm{X}} \mathrm{J}_{x}
$$

An embedded Type-2 set “ $\widetilde{\mathrm{A}}_{\mathrm{e}}$ ” for discrete universes of discourse " $X$ " and " $U$ " has " $N$ " elements, where “ $\widetilde{\mathrm{A}}_{\mathrm{e}}$ " contains exactly one element from $\mathrm{J}_{x_{1}}=\mathrm{J}_{x_{2}}=\ldots=\mathrm{J}_{x_{\mathrm{N}}}$, namely, $\mathrm{u}_{1}=\mathrm{u}_{2}=\ldots=\mathrm{u}_{\mathrm{N}}$. Each element has an associated secondary grade as follows:

$$
\begin{aligned}
& f_{\mathrm{x}_{1}}\left(\mathrm{u}_{1}\right)=f_{\mathrm{x}_{2}}\left(\mathrm{u}_{2}\right)=\ldots . .=f_{\mathrm{x}_{\mathrm{N}}}\left(\mathrm{u}_{\mathrm{N}}\right) \text { i.e., } \\
& \tilde{A}_{e}=\sum_{i=1}^{N}\left[f_{x_{i}}\left(u_{i}\right) / u_{i}\right] / x_{i} \quad \mathrm{u}_{\mathrm{i}} \in \mathrm{J}_{x_{i}} \subseteq \mathrm{U}=[0,1]
\end{aligned}
$$

\section{SimULATION RESULTS}

An MRAS speed estimator for sensorless DTFC-SVPWM of an IM drive using two different adaptation mechanism schemes are developed in the MATLAB/Simulink environment and in real-time systems to validate its effectiveness. The performance of each adaptation mechanism scheme is tested in both speed sensor (encoder/tachometer) and speed sensorless (rotor speed estimation) modes of operation. The IMD machine rating and parameters are illustrated in Table II.

\section{A. Under 9 N.m Load Torque Operation}

The performance of the MRAS speed senseless DTFC-SVPWM of an IMD is simulated in forward and reversal modes of operation under a sudden load torque condition of 9 N.m using two different adaptation schemes. The sudden load torque of 9 N.m is applied at $0.7 \mathrm{~s}$ intervals and removed at $0.9 \mathrm{~s}$ in the forward mode as shown in Fig. 7. A load torque of -9 N.m is applied at $2.2 \mathrm{~s}$ and removed at
TABLE II

PARAMETER VALUES OF IMDS

\begin{tabular}{ll}
\hline \multicolumn{1}{c}{ Parameters } & Nominal values \\
\hline Stator Resistance $(R s)$ & $5.5 \Omega$ \\
Rotor Resistance $(R r)$ & $4.51 \Omega$ \\
Mutual Inductance $(L m)$ & $0.2919 \mathrm{H}$ \\
Stator Inductance $(L s)$ & $0.3065 \mathrm{H}$ \\
Rotor Inductance $(L r)$ & $0.3065 \mathrm{H}$ \\
Inertia $(J)$ & $0.089 \mathrm{Kg} \cdot \mathrm{m}^{2}$ \\
Frequency $(F)$ & $50 \mathrm{~Hz}$ \\
Speed $\left(W_{e}\right)$ & $1410 \mathrm{rpm}$ \\
\hline
\end{tabular}

$2.4 \mathrm{~s}$ in the reversal mode of operation as shown in Fig. 8. The simulation results show that when an application of sudden load torque is applied to the motor, a large speed drop occurs at approximately $1.88 \mathrm{rpm}$ with a steady-state error of $0.17 \mathrm{rpm}$, and high ripple contents of torque and stator current using T1FLC were observed. A slight speed drop of $0.47 \mathrm{rpm}$ occurs with a steady-state error of $0.12 \mathrm{rpm}$, and less ripple contents of torque and stator current using T2FLC-based adaptation scheme were observed.

\section{B. Sudden Change in Speed Operation}

The IMD performance was simulated under different sudden changes in speed conditions (Fig. 9). The sudden change in speed from $600 \mathrm{rpm}$ to $900 \mathrm{rpm}$ was applied at 0.7 $\mathrm{s}$, whereas that from $900 \mathrm{rpm}$ to $1200 \mathrm{rpm}$ was applied at 1.3 s. The settling time of the estimated rotor speed from $0 \mathrm{rpm}$ to $600 \mathrm{rpm}$ was $0.25 \mathrm{~s}$ with T1FLC, whereas the settling time was $0.22 \mathrm{~s}$ with the T2FLC-based adaptation mechanism. The ripple contents of electromagnetic torque was high at approximately 1.98 N.m using the T1FLC scheme, whereas a small ripple was generated at approximately 0.95 N.m using the T2FLC-based adaptation scheme. A comparison of the controllers is listed in Table III.

\section{REAL-TIME TESTING}

The MRAS speed estimator for sensorless DTFC-SVPWM of an IM drive using two different adaptation mechanism schemes are implemented in a real-time system to verify its feasibility and effectiveness. The real-time system was developed using a dSPACE-1104 controller board containing a TMS320F240 slave processor and an analog-to-digital converter (ADC) interface board CP1104. The dSPACE-1104 controller board is installed on an Intel(R) Core(TM) i7-4770 CPU $3.50 \mathrm{GHz}$ PC for software development and result visualization. The PWM pulses were generated by the TMS320F240 slave processor, which were fed into the gate driver of the three-phase voltage source inverter through a processing card. The voltage source inverter drives a four-pole, $1.5 \mathrm{~kW}$ induction motor with a switching frequency of $5 \mathrm{kHz}$. The Hall-effect current sensors (LA55P) 


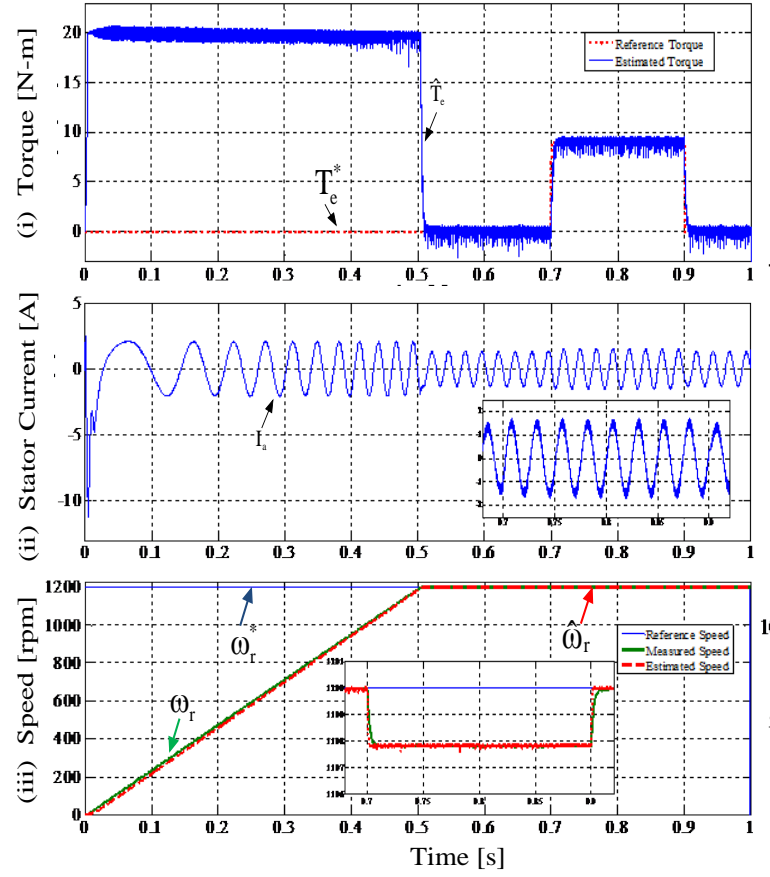

(a)
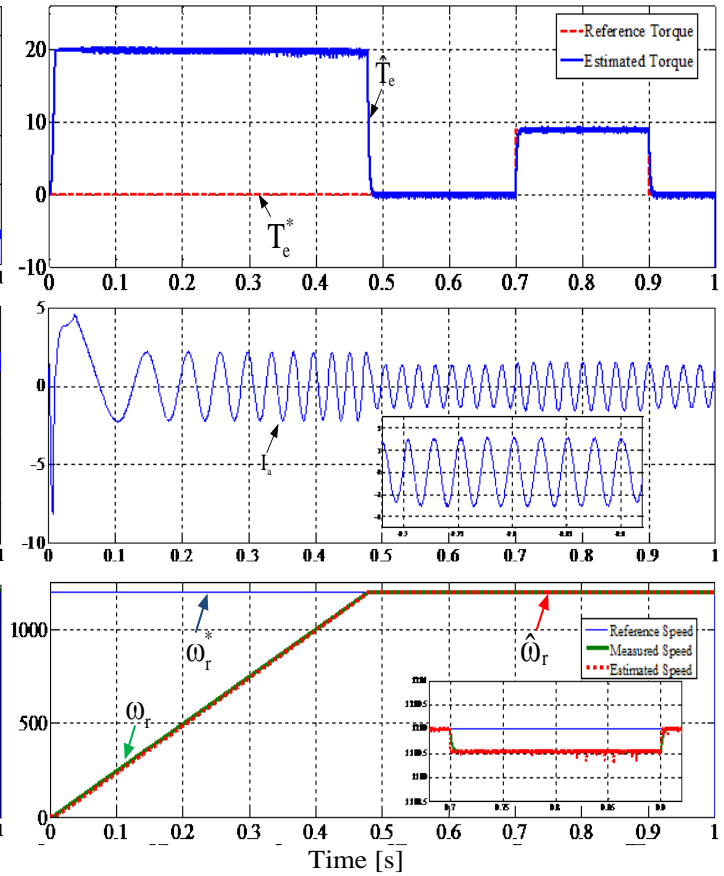

(b)

Fig. 7. Simulation responses of IMD under $1200 \mathrm{rpm}$ with a load torque of 9 N.m operating conditions in forward motoring using, (a) T1FLC-based adaptation mechanism: (i) Torque, (ii) Stator current, and (iii) Rotor speed. (b) T2FLC-based adaptation mechanism: (i) Torque, (ii) Stator current, and (iii) Rotor speed.
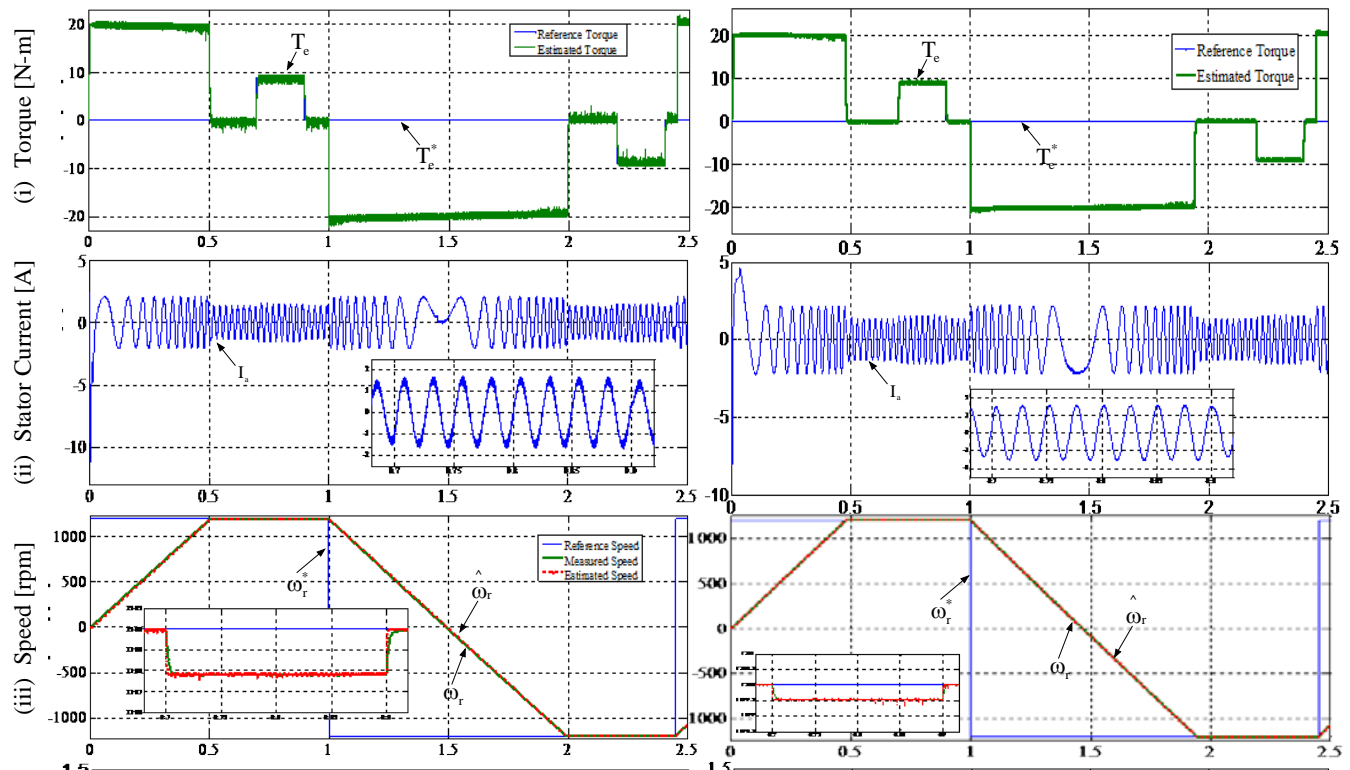

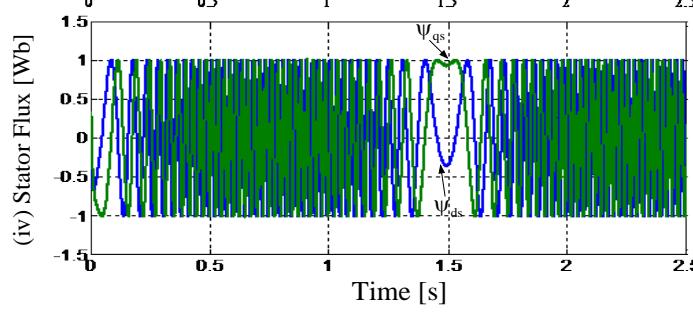

(a)

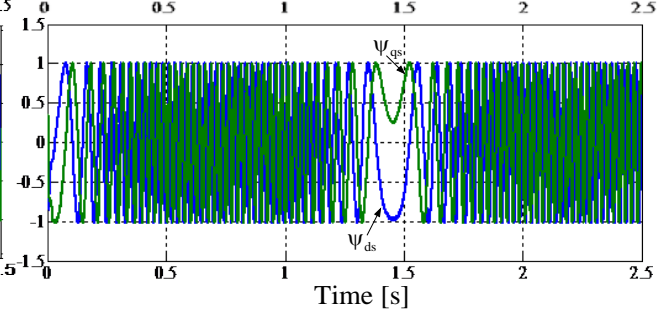

(b)

Fig. 8. Simulation responses of an IMD under $-1200 \mathrm{rpm}$ with a load torque of 9 N.m operating conditions using, (a) T1FLC-based adaptation mechanism: (i) Torque, (ii) stator current, (iii) rotor speed, and (iv) stator flux. (b) T2FLC-based adaptation mechanism: (i) Torque, (ii) stator current, (iii) rotor speed, and (iv) stator flux. 

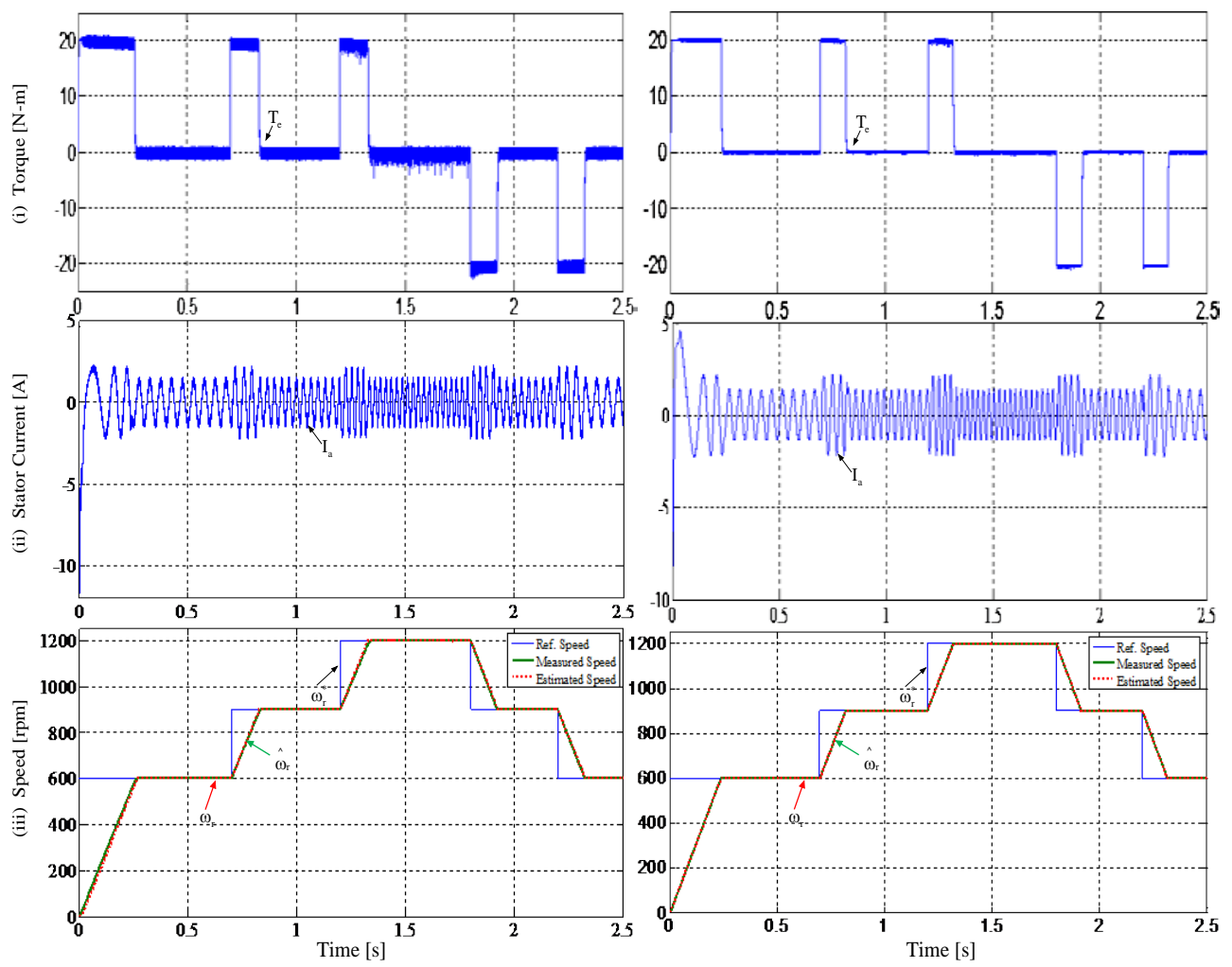

(a)

(b)

Fig. 9. simulation responses of IMD under sudden changes in speed operating conditions using, (a) T1FLC-based adaptation mechanism: (i) Torque, (ii) Stator current, and (iii) Rotor speed. (b) T2FLC-based adaptation mechanism: (i) Torque, (ii) Stator current, and (iii) Rotor speed.

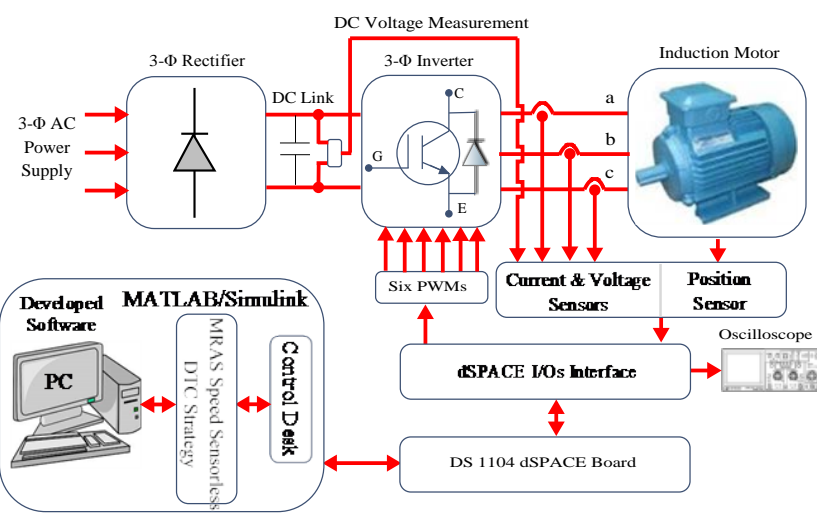

Fig. 10. Schematic of the real-time set-up of an MRAS speed estimator for speed sensorless DTFC-SVPWM of an IMD.

TABLE III

COMPARISON OF THE CONTROLLERS

\begin{tabular}{lcc}
\hline \multicolumn{1}{c}{ Type of controller } & T1FLC & T2FLC \\
\hline Torque ripples (N.m) & 1.98 & 0.95 \\
Current ripples (A) & 0.28 & 0.08 \\
$\begin{array}{l}\text { Speed drops under load torque } \\
\text { (rpm) }\end{array}$ & 1.88 & 0.47 \\
Steady-state error speed (\%) & 0.17 & 0.12 \\
Settling time (s) & 0.50 & 0.478 \\
Disturbance rejection & Good & Excellent \\
Robustness & Good & Excellent \\
\hline
\end{tabular}

were used to measure the motor line currents and read by the ADC of the power PC in the dSPACE-1104 controller board. The motor speed was measured by a speed encoder/tachometer. Variables such as line current and motor speed were observed using a digital-to-analog converter (DAC). The real-time setup of the MRAS speed estimator for the speed sensorless DTFC-SVPWM of an IMD is shown in Fig. 10.

\section{A. Real-Time Results}

The real-time system of an MRAS speed sensorless DTFC-SVPWM of an IMD was investigated when an IM drive operated under load, no load, and sudden changes in speed operating conditions.

The real-time performance of an IM drive was initially tested under a load torque of 9 N.m condition. The sudden load torque of 9 N.m was applied at a time interval of $0.7 \mathrm{~s}$ in forward motoring as shown in Fig. 11. A load torque of -9 N.m was applied at $2.2 \mathrm{~s}$ in reversal motoring when an induction motor operated at $1200 \mathrm{rpm}$ as shown in Fig. 12. Real-time results show that a sudden application of the load torque causes a large drop in the rotor speed with a high steady-state error using T1FLC and a momentary drop in the rotor speed with a less steady state error using the T2FLC-based adaptation scheme. 


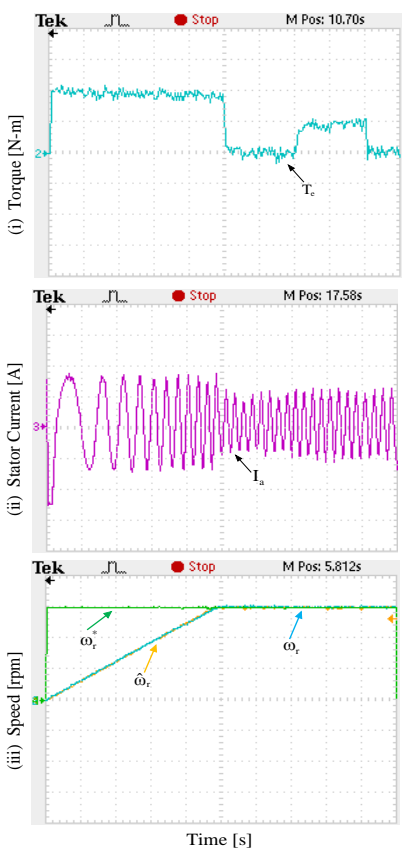

(a)

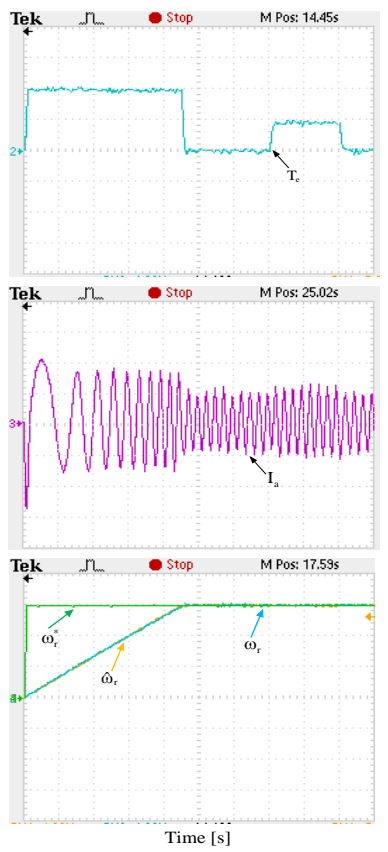

(b)
Fig. 11. Real-time responses of the IMD under $1200 \mathrm{rpm}$ with a load torque of 9 N.m operating in forward motoring conditions using, (a) T1FLC-based adaptation mechanism: (i) Torque, (ii) Stator current, and (iii) Rotor speed. (b) T2FLC-based adaptation mechanism: (i) Torque, (ii) Stator current, and (iii) Rotor speed.

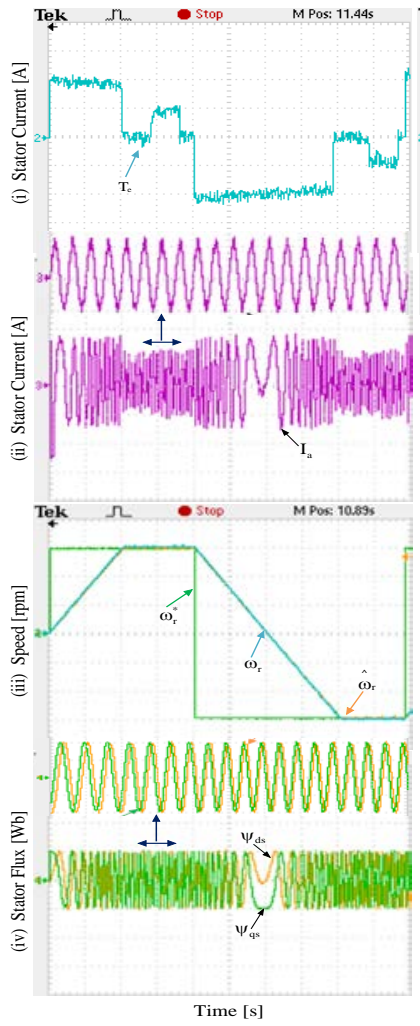

(a)
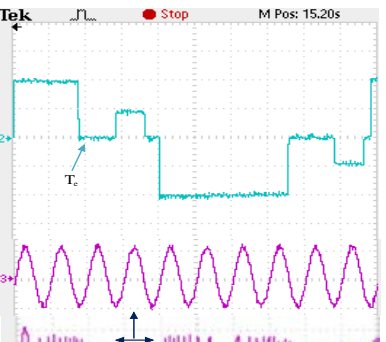
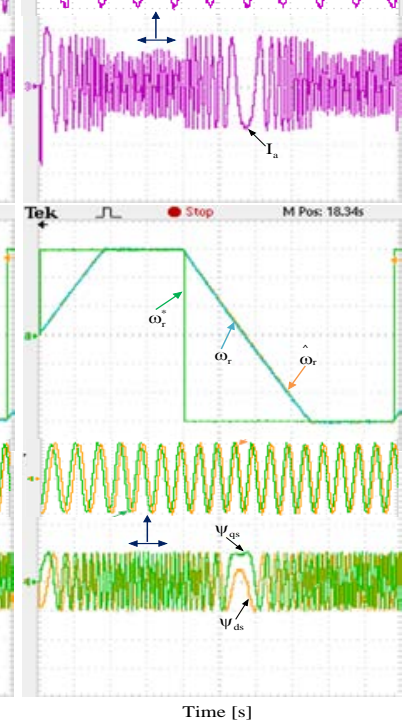

(b)

Fig. 12. Real-time responses of the IMD under $-1200 \mathrm{rpm}$ with a load torque of 9 N.m operating conditions using, (a) T1FLC-based adaptation mechanism: (i) Torque, (ii) Stator current, and (iii) Rotor speed. (b) T2FLC-based adaptation mechanism: (i) Torque, (ii) Stator current, and (iii) Rotor speed.

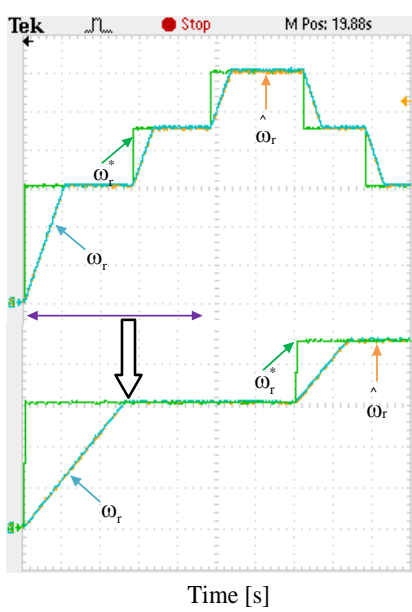

(a)

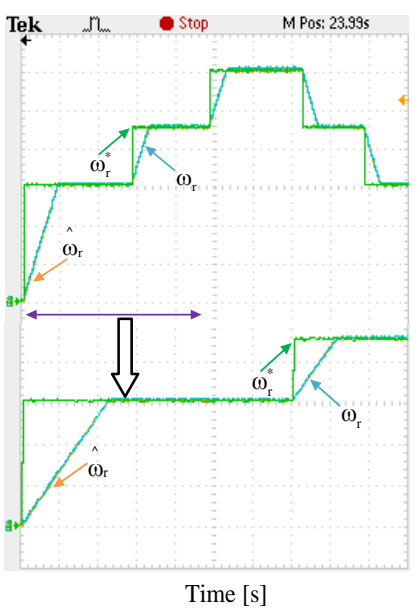

(b)
Fig. 13. Real-time responses of an IMD under sudden changes in speed operating conditions using (a) T1FLC and (b) T2FLC.

(a). T1FLC

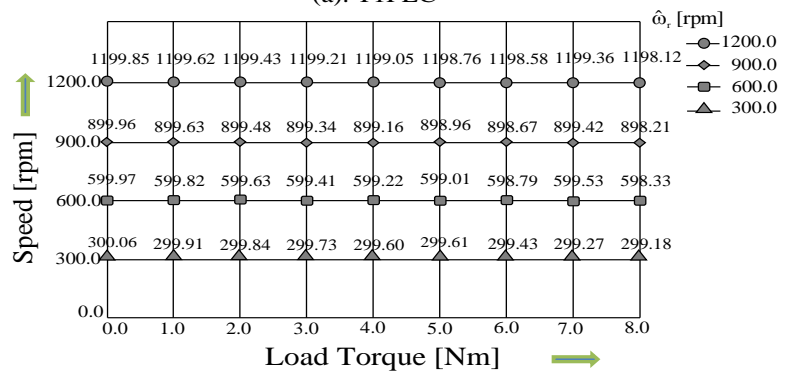

(b). T2FLC

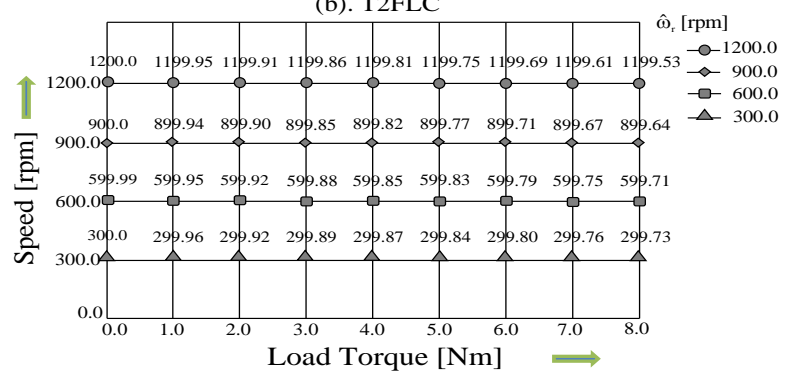

Fig. 14. Real-time rotor speed response under low-, medium-, and high-load torque with different speed operating conditions.

The real-time performance of an IMD tested under sudden changes in speed is shown in Fig. 13. The rotor speed reached its reference speed faster, and the ripple contents of the stator current and torque were less using T2FLC compared with the T1FLC scheme as shown in Fig. 13.

The performance of the MRAS speed sensorless DTFC-SVPWM of an IMD was also tested and compared under different speeds that operate under low-, medium-, and high-load torque conditions using two adaptation mechanism schemes, as shown in Fig. 14. The real-time responses illustrate that the system shows high robustness to different load torque disturbances and sudden changes in speed conditions using the T2FLC-based adaptation scheme compared with the T1FLC-based adaptation scheme. 


\section{CONCLUSION}

A rotor-flux MRAS speed estimator for speed sensorless DTFC-SVPWM of an IMD using two adaptation mechanism schemes are implemented in this study. The T1FLC scheme is implemented first; it produces a large speed drop when a sudden application of the load torque is applied to the IMD, and high ripple contents of stator current and estimated torque are observed. Furthermore, the T2FLC scheme is developed, which shows excellent dynamic and steady-state performance. It is also robust to different load torque disturbances and sudden changes in speed conditions. A detailed comparison of the two different adaptation schemes is conducted under no load, load, and sudden changes in the speed operating conditions. The simulation and real-time system verification confirm that the T2FLC strategy shows better dynamic and steady-state performance of the stator current, torque, and rotor speed compared with the T1FLC-based adaptation mechanism scheme.

\section{REFERENCES}

[1] G. S. Buja and M. P. Kazmierkowski, "Direct torque control of PWM inverter-fed AC motors-a survey," IEEE Trans. Ind. Electron., Vol. 51, No. 4, pp. 744-757, Aug. 2004.

[2] F. Blaschke, "The principle of field-orientation as applied to the transvector closed-loop control system for rotating-field machines.” Siemens Review, Vol. 34, No. 3, pp. 217-220, Mar. 1972.

[3] I. Takahashi and T. Noguchi, "A new quick-response and high-efficiency control strategy of an induction motor." IEEE Trans. Ind. Appl., Vol. 5, No. 5, pp: 820-827, Apr. 1986.

[4] C. Lascu, I. Boldea, and F. Blaabjerg, "A modified direct torque control for induction motor sensorless drive," IEEE Trans. Ind. Appl., Vol. 36, No.1, pp. 122-130, Jan./Feb. 2000.

[5] J. Faiz, M. B. B. Sharifian, A. Keyhani, and A. B. Proca, "Sensorless direct torque control of induction motors used in electric vehicle," IEEE Trans. Energy Convers., Vol. 18, No. 1, pp. 1-10, Mar. 2003.

[6] J. Holtz, "Sensorless control of induction machines - with or without signal injection," IEEE Trans. Ind. Electron., Vol. 53, No. 1, pp. 7-30, Feb. 2006.

[7] J. Maes and J. A. Melkebeek, "Speed-sensorless direct torque control of induction motors using an adaptive flux observer,” IEEE Trans. Ind. Appl., Vol. 36, No. 3, pp. 778-785, May/Jun. 2000.

[8] C. M. Lee, and C. L. Chen, “Observer-based speed estimation method for sensorless vector control of induction motors," IET Control Theory and Applications, Vol. 145, No. 3, pp. 359-363, May 1998.

[9] M. F. Iacchetti, M. S. Carmeli, F. C. Dezza, and R. Perini, "A speed sensorless control based on a MRAS applied to a double fed induction machine drive," Electrical Engineering, Vol. 91, No. 6, pp: 337-345, Jan. 2010.

[10] M. Rashed and A. F. Stronach, "A stable back-EMF MRAS-based sensorless low-speed induction motor drive insensitive to stator resistance variation," IEE Proc. Electric Power Appl., Vol. 151, No. 6, pp. 685-693, Nov. 2004.
[11] S. M. Gadoue, D. Giaouris, and J. W. Finch, "MRAS sensorless vector control of an induction motor using new sliding-mode and fuzzy-logic adaptation mechanisms," IEEE Trans. Energy Convers., Vol. 25, No. 2, pp. 394-402, Jun. 2010.

[12] S. Maiti, C. Chakraborty, Y. Hori, and M. C. Ta, "Model reference adaptive controller-based rotor resistance and speed estimation techniques for vector controlled induction motor drive utilizing reactive power," IEEE Trans. Ind. Electron., Vol. 55, No. 2, pp. 594-601, Feb. 2008.

[13] H. M. Kojabadi, "Active power and MRAS based rotor resistance identification of an IM drive," Simulation Modelling Practice and Theory, Vol. 17, No. 2, pp. 376-389, Feb. 2009.

[14] C. Schauder, “Adaptive speed identification for vector control of induction motors without rotational transducers,” IEEE Trans. Ind. Appl., Vol. 28, No. 5, pp. 1054-1061, Sep./Oct. 1992.

[15] M. Comanescu and L. Xu, "Sliding-mode MRAS speed estimators for sensorless vector control of induction machine,” IEEE Trans. Ind. Electron., Vol. 53, No. 1, pp. 146-153, Feb. 2006.

[16] V. M. Panchade, R. H. Chile, and B. M. Patre, "A survey on sliding mode control strategies for induction motors," Annual Reviews in Control, Vol. 37, No. 2, pp. 289-307, Dec. 2013.

[17] Y. Zhang, J. Zhu, Z. Zhao, W. Xu, and D. G. Dorrell, “An improved direct torque control for three-level inverter-fed induction motor sensorless drive," IEEE Trans. Power Electron., Vol. 27, No. 3, pp. 1502-1513, Mar. 2012.

[18] L. A. Zadeh, "Fuzzy sets," Information and Control, Vol. 8, No. 3, pp. 338-353, Jun. 1965.

[19] H. Li, A. Monti, and F. Ponci, "A fuzzy-based sensor validation strategy for Ac motor drives.” IEEE Trans. Ind. Informat., Vol. 8, No. 4, pp. 839-848, Nov. 2012.

[20] C. M. F. S. Reza, M. D. Islam, and S. Mekhilef, “A review of reliable and energy efficient direct torque controlled induction motor drives," Renewable and Sustainable Energy Reviews, Vol. 37, No. 10, pp. 919-932, Sep. 2014.

[21] M. N. Uddin and M. Hafeez, "FLC-based DTC scheme to improve the dynamic performance of an IM drive," IEEE Trans. Ind. Appl., Vol. 48, No. 2, pp. 823-831, Mar./Apr. 2012.

[22] N. V. Naik and S. P. Singh, "Improved torque and flux performance of type-2 fuzzy-based direct torque control induction motor using space vector pulse-width modulation," Electric Power Components and Systems, Vol. 42, No. 6, pp. 658-669, Mar. 2014.

[23] J. M. Mendel, R. I. John, and F. Liu, "Interval type-2 fuzzy logic systems made simple,” IEEE Trans. Fuzzy Syst., Vol. 14, No. 6, pp. 808-821, Dec. 2006.

[24] D. Wu, "Approaches for reducing the computational cost of interval type-2 fuzzy logic systems: Overview and comparisons," IEEE Trans. Fuzzy Syst., Vol. 21, No. 1, pp. 80-99, Feb. 2013.

[25] Q. Liang and J. M. Mendel, "Interval type-2 fuzzy logic systems: Theory and design," IEEE Trans. Fuzzy Syst., Vol. 8, No. 5, pp. 535-550, Oct. 2000.

[26] S. Mikkili and A. K. Panda, "Types-1 and-2 fuzzy logic controllers-based shunt active filter I d-I q control strategy with different fuzzy membership functions for power quality improvement using RTDS hardware," IET Power Electron., Vol. 6, No. 4, pp. 818-833, Apr. 2013.

[27] Z. Sun, N. Wang, D. Srinivasan, and Y. Bi, “Optimal tuning 
of type-2 fuzzy logic power system stabilizer based on differential evolution algorithm," Inter. Journal of Electrical Power \& Energy Sys., Vol. 62, No. 5, pp. 19-28, Nov. 2014.

[28] P. Melin and O. Castillo, “A review on type-2 fuzzy logic applications in clustering, classification and pattern recognition,” Applied Soft Comp., Vol. 21, No. 8, pp. 568-577, Aug. 2014.

[29] L. A. Zadeh, "The concept of a linguistic variable and its application to approximate reasoning-I," Information sciences, Vol. 8, No. 3, pp. 199-249, Mar. 1975.

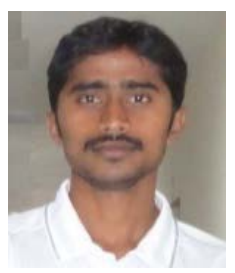

Tejavathu Ramesh was born in Banapuram Thanda, Khammam, Andhra Pradesh, India, on April 9, 1987. He received his B.Tech degree in 2009 in from the Department of Electrical and Electronics Engineering of Gokaraju Rangaraju Institute of Engineering and Technology (GRIET), which is affiliated with JNTU Hyderabad, Andhra Pradesh, India. He then received his Masters (M.Tech) from the Department of Electrical Engineering, N.I.T Rourkela, Orissa, India, in 2011. He is currently working as an assistant professor at the Department of Electrical Engineering of the National Institute of Technology Kurukshetra while pursuing his Ph.D at the Department of Electrical Engineering of the National Institute of Technology Rourkela, India. His main areas of research include power electronics and drives, applications of soft computing techniques, and artificial intelligence.

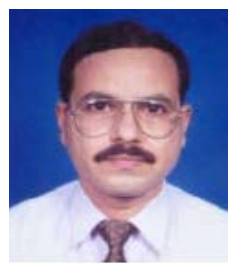

Anup Kumar Panda received his B.Tech in Electrical Engineering from Sambalpur University, India in 1987. He received his M.Tech in Power Electronics and Drives from the Indian Institute of Technology, Kharagpur, India in 1993, and his Ph.D. from Utkal University in 2001. He joined IGIT, Sarang as part of the faculty in 1990. He served there for 11 years and then joined the National Institute of Technology, Rourkela in January 2001 as an assistant professor. He is currently a professor at the Department of Electrical Engineering. He has published over 100 articles in journals and conferences. He has completed two MHRD projects and one NaMPET project. He has supervised six Ph.D. scholars and is currently supervising six scholars in the area of power electronics and drives. His research interests include the analysis and design of high-frequency power conversion circuits, power factor correction circuits, power quality improvement in power systems and electric drives, and applications of soft computing techniques.

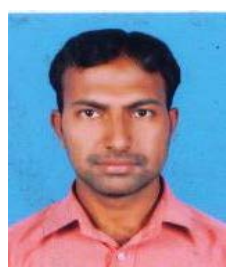

S. Shiva Kumar received his B.Tech in Electrical Engineering from GRIET, which is affiliated with the Jawaharlal Nehru Technological University (JNTUK), India in 2009. He then received his M.Tech in Power Electronics and Drives also from GRIET in 2011. He is currently pursuing his Ph.D. at the National Institute of Technology Rourkela. He worked as a faculty in GRIET Hyderabad from 2010 for approximately one year. His research interest includes the analysis and design of high-frequency power conversion circuits, power factor correction circuits, SMPS, electric drives, and hybrid electric vehicles. 